\title{
Metástasis adrenal de carcinoma pulmonar
}

\author{
J. I. Rodríguez-Hermosa, J. Roig, P. Ortuño ${ }^{1}$, A. M. Quiles ${ }^{1}$, M. Recasens ${ }^{2}$ y A. Codina-Cazador \\ Servicios de Cirugía General y Digestiva, 'Radiodiagnóstico y ${ }^{2}$ Endocrinología. Hospital Universitario Dr. Josep Trueta. \\ Girona
}

\section{INTRODUCCIÓN}

Las metástasis adrenales solitarias son poco frecuentes y su resección resulta controvertida. También se discute su abordaje laparoscópico. Generalmente se identifican en los controles de seguimiento oncológico tras la exéresis de diversos cánceres primarios, siendo los más frecuentes los pulmonares, seguidos de los renales, colorrectales, laríngeos y melanomas (1).

\section{CASO CLÍNICO}

Varón de 59 años con antecedentes de hipertensión arterial, enfermedad pulmonar obstructiva crónica (exfumador), obesidad tipo I (IMC $30,5 \mathrm{~kg} / \mathrm{m}^{2}$ ) y dislipemia. Intervenido de neoplasia pulmonar realizándose bilobectomía derecha; la anatomía patológica informó de carcinoma escamoso poco diferenciado (PT2N1M0). Tras permanecer libre de enfermedad durante 10 meses se diagnostica una tumoración adrenal izquierda por TC abdominal (Figs. 1 y 2), confirmándose mediante PAAF que era una metástasis. Se efectuó un abordaje laparoscópico, con descenso del ángulo esplénico del colon y movilización medial espleno-pancreática. Al exponer la glándula adrenal se observa una infiltración tumoral de la

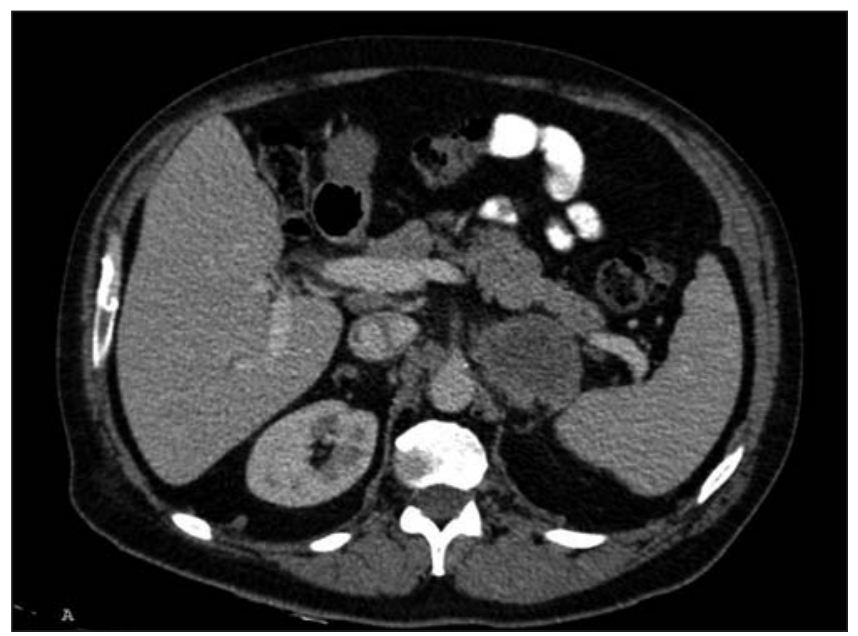

Fig. 1. Tomografía computarizada abdominal, proyección axial: masa adrenal izquierda, de 5,6 x 4,6 cm, con centro hipodenso con cierto grado de necrosis.

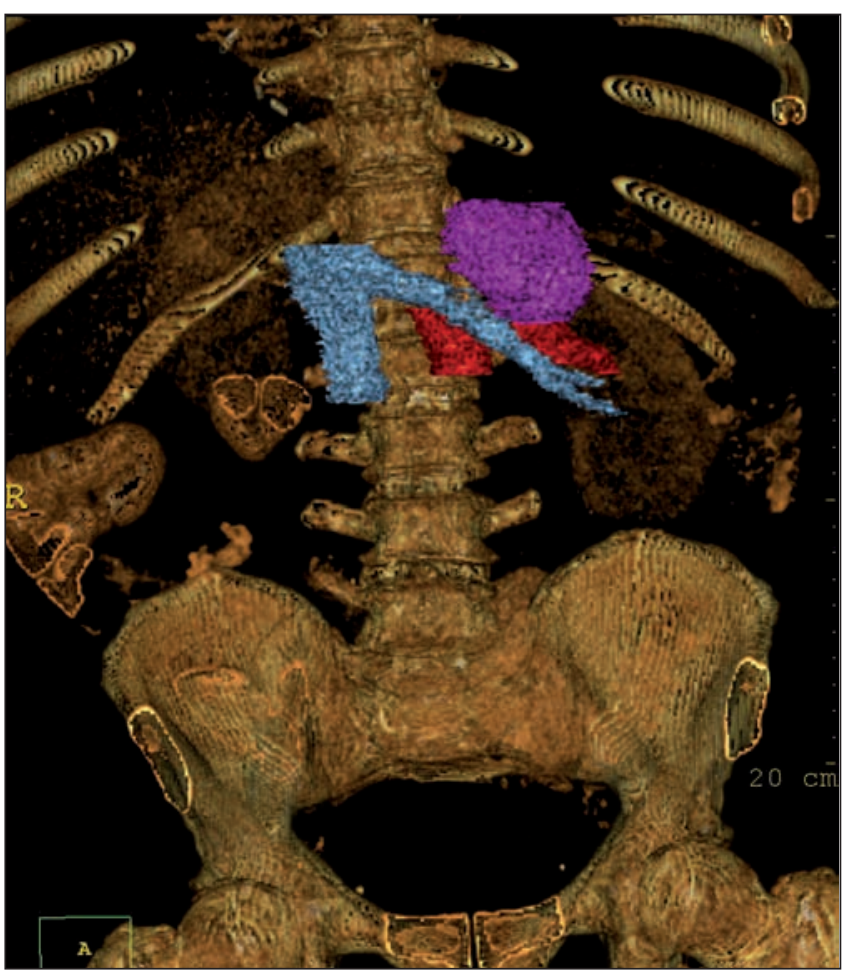

Fig. 2. Reconstrucción tomográfica abdominal 3D, proyección coronal oblicua: tumoración adrenal izquierda sin aparente afectación vascular renal. 
arteria y la vena renal, por lo se convierte a cirugía abierta realizándose una exéresis en bloque del riñón y la suprarrenal izquierda. El diagnóstico definitivo fue de metástasis suprarrenal izquierda por un carcinoma escamoso poco diferenciado y afectación vascular de la arteria y la vena renal, con un parénquima renal normal. Tras la cirugía el paciente permanece asintomático, con un intervalo libre de enfermedad en la actualidad de 15 meses.

\section{DISCUSIÓN}

Las metástasis adrenales solitarias deben ser abordadas quirúrgicamente, ya que sólo la resección ha obtenido curaciones aisladas y supervivencias prolongadas, en contraposición a la radioterapia y/o quimioterapia (1).

Las supervivencias con tratamientos no quirúrgicos oscilan entre 6 y 8,5 meses, en contraposición con la resección laparoscópica que oscilan entre los 13 y 40 meses (1).

La adrenalectomía laparoscópica puede realizarse sin ninguna desventaja oncológica. Se debe ofrecer a pacientes con enfermedad resecable, intervalo libre de enfermedad $>6$ meses y un tamaño tumoral resecable mediante esta técnica laparoscópica (1).

Los motivos que ocasionan la conversión a cirugía abierta, en el abordaje laparoscópico adrenal, suelen ser las hemorragias, las dificultades en la disección y los procesos infiltrativos malignos (2).

La adrenalectomía laparoscópica podría llegar a ser el tratamiento de elección de los tumores malignos $(3,4)$. Las actuales limitaciones de la laparoscopia son dependientes de la experiencia del cirujano y no de las técnicas mínimamente invasivas (4).

\section{BIBLIOGRAFÍA}

1. Silvio L, Madrazo Z, Pujol J, Masdevall C, Rafecas A, Moreno P. Adrenalectomía laparoscópica por sospecha de metástasis adrenal solitaria. Cir Esp 2007; 81: 197-201.

2. Lamas S, Pujol J, García-Barrasa A, Mora L, Moreno P, Rafecas A, Jaurrieta E. Adrenalectomía laparoscópica: causas de conversión, experiencia personal y revisión de la bibliografía. Cir Esp 2004; 75: 18-22.

3. Assalia A, Gagner M. Laparoscopic adrenalectomy. Br J Surg 2004; 91: 1259-74.

4. Gumbs AA, Gagner M. Laparoscopic adrenalectomy. Best Pract Res Clin Endocrinol Metab 2006; 20: 483-99. 